\title{
Copper nano-sol loaded woven fabrics: structure and color characterization
}

\author{
Pragnya Kanade* ${ }^{*}$ and Bharat Patel
}

\section{*Correspondence:}

pragnyakanade@yahoo.co.in

Maharaja Sayajirao University

of Baroda, Vadodara, Gujarat, India

\begin{abstract}
Nano technology is an upcoming branch where lot of research work is being done with the intention of improving/changing properties of the materials. In this study polyester, cotton and polyester-cotton blended fabrics were coated with copper nano particles by pad-dry-cure technique. The morphology of nano-composite fabrics characterized using scanning electron microscope reveals that nanoparticles were dispersed on the fabric samples. The elemental analysis for confirming the presence of copper in the fabric samples was done using the Fourier transform infrared spectroscopy and energy dispersive $X$-ray spectroscopy techniques. The $X$-ray diffraction analysis of the fabric samples helped to unveil that incorporation of copper nano particles increased the $d$-spacing value in polyester fabric to a greater extent in comparison to the cotton and polyester-cotton blended fabrics. The nano treated woven fabric samples were dyed using myrobolan; a natural dye. The samples were evaluated in terms of colourimetric parameters and colour fastness. The copper nano-sol treatment was found to improve both K/S and colour fastness.
\end{abstract}

Keywords: Copper nano, Cotton, Morphology, Dyeing, Natural dye, Polyester, Polymer structure

\section{Introduction}

Nano particles have at least one dimension as $100 \mathrm{~nm}$ or less. Owing to higher surface areas nano materials can be highly reactive; hence find their application in variety of fields like medicine, electronics, food, fuel cells, batteries, water treatment, chemical sensors, pharmaceuticals, dairy industry, textiles etc. Its application is sought in textiles, to achieve improvement or change in property of the raw material or improvement in its functional properties (Chattopadhyay and Patel 2009, 2010; Patel and Chattopadhyay 2007; Patel and Patel 2012). Currently nano technology is used in textiles with the aim of furthering functional properties like dyeing, resistance to shrinkage, wrinkling, staining and flammability.

Nano application is also opted for improving the ultra violet (UV) protection, water repellency, and in odor and moisture management. They have capability to provide self cleaning and anti-bacterial properties making them popular for intimate as well as non intimate applications. In short the type of effect achieved like self cleaning/antibacterial/ UV resistant and so on, is greatly dependent on the choice of nano material selected and 
its inherent characteristics (Patel et al. 2014; Bhattacharya and Chaudhari 2014; Shaikh et al. 2015; Chattopadhyay and Patel 2012).

Besides the nano material (filler) chosen, its degree of dispersion greatly influences the enhancement efficiency. To attain excellent properties, it is however very important that the average size of fillers present must be in the nano-meter size along with fine particle distribution in the polymer matrix after its application. Copper nanoparticles have shown a great potential as the nano-filler for hygiene application and in making textiles electrically conductive (Chattopadhyay and Patel 2011, 2012, 2013, 2014a, b).

The present study reports observations when $100 \%$ polyester ('p'), $100 \%$ cotton ('c') and polyester-cotton blended ( $\mathrm{p}-\mathrm{c}$; 50:50) fabric samples were treated with copper nano sol. The properties of nano-composite fabrics were evaluated in terms of morphological and chemical changes. The surface morphology has been observed using scanning electron microscopy (SEM). The chemical transformation has been analyzed using Fourier transform infrared spectroscopy (FT-IR), energy dispersive X-ray spectroscopy (EDS) and X-ray diffraction (XRD) technique (http://www.intechopen.com/books/fourier-transforms-new-analyticalapproaches-and-ftir-strategies/ applications-offourier-transform-infrared-spectroscopy-to-study-cotton-fibers).

\section{Methods}

Fabric

Three fabric samples; 100\% 'p', 100\% 'c' and p-c blend (50:50; intimate), all with plain weave (p.w) were collected from market. These fabrics were then subjected to light scouring before application of any treatment to them $[5$ g per liter (gpl) of nonionic detergent and $2 \mathrm{gpl}$ of sodium carbonate were mixed in water and boiled for $15 \mathrm{~min}$ ]. Fabric specifications are mentioned in Table 1.

\section{Dyes and chemicals}

Myrobolan (C.I. Natural brown 6) was used as received for this study without further purification. Copper sulphate, sodium borohydride and tri-sodium citrate of analytical grade purity were procured from Sd Fine Chemicals, India.

\section{Preparation of copper nano sol}

Copper nano colloidal sol was prepared from copper salt by chemical reduction technique (Chattopadhyay and Patel 2010). "0.3 $\mathrm{g} \mathrm{CuSO}_{4}$ was dissolved in $100 \mathrm{ml}$ of distilled water. It was then kept in the reaction chamber and was slowly reduced by drop wise

Table 1 Polyester, cotton and polyester-cotton fabric specifications

\begin{tabular}{lllllll}
\hline Fabric sample & \multicolumn{6}{l}{ Fabric specifications } \\
\cline { 2 - 6 } & \multicolumn{2}{l}{ Count (English) } & Ends/inch & Picks/inch & Weave & Fabric weight g/sq.mt \\
\cline { 2 - 6 } & Warp & Weft & & & & \\
\hline Polyester & 61.38 & 37.07 & 132 & 96 & p.w & 120 \\
Cotton & 32.63 & 33.9 & 88 & 60 & p.w & 101 \\
P-C blend & 35.48 & 35.63 & 100 & 74 & p.w & 120 \\
\hline
\end{tabular}

p.w plain woven fabric 
addition of very dilute chilled solution of sodium borohydride $\left(\mathrm{NaBH}_{4}, 0.1 \mathrm{~g}\right.$ dissolved in $50 \mathrm{ml}$ distilled water) in nitrogen atmosphere. During the entire reaction process, the solution mixture was stirred vigorously. As the color of the solution turned to light yellow; $5 \mathrm{ml}$ of trisodium citrate $\left(\mathrm{C}_{6} \mathrm{H}_{5} \mathrm{Na}_{3} \mathrm{O}_{7} \cdot 2 \mathrm{H}_{2} \mathrm{O}, 0.1 \mathrm{~g}\right.$ dissolved in $100 \mathrm{ml}$ distilled water), was added drop by drop with vigorous stirring" (Patel and Chattopadhyay 2007). $5 \mathrm{~g}$ Lissapol $\mathrm{L}$ as surfactant was added to $100 \mathrm{ml}$ of copper nano sol coating solution. The mixture was then stirred using magnetic stirrer at $250 \mathrm{rpm}$ for $30 \mathrm{~min}$ at $60{ }^{\circ} \mathrm{C}$ temperature.

\section{Preparation of nano copper composite fabrics}

The padding liquor was applied to the 'p', 'c' and p-c fabric samples (size: $40 \times 30 \mathrm{~cm}$ ) by dipping them in the dispersion for $10 \mathrm{~min}$. After which they were padded on an automatic padding mangle machine, operating at $15 \mathrm{rpm}$ and $1.75 \mathrm{~kg} / \mathrm{cm}^{2}$ pressure; using 2-dip-2-nip padding sequence at $70 \%$ expression. The padded substrates were dried at $80{ }^{\circ} \mathrm{C}$ for $5 \mathrm{~min}$ and cured in a preheated curing oven. Curing of 'p', 'c' and $\mathrm{p}-\mathrm{c}$ fabric samples was done in oven at temperatures of 140,120 and $130{ }^{\circ} \mathrm{C}$ respectively for $3 \mathrm{~min}$.

\section{Characterization of nanoparticles}

The morphology and elemental analysis of the synthesized nanoparticles was performed using SEM (Model JSM5610LV, version 1.0, Jeol, Japan) using Oxford-Inca software (U.K.). The copper nanoparticles were examined after depositing on carbon coated aluminum sheet and further coating with gold $(\mathrm{Au})$.

\section{Characterization of fabric samples}

The surface morphology of the copper loaded nano 'p', 'c' and p-c blended fabric was observed on SEM (Model JSM5610LV, version 1.0, Jeol, Japan). The presence of copper in composite fabric was confirmed by elemental analysis using Oxford-Inca software (U.K.) on the same instrument. The chemical composition of the composite material was further analyzed using FT-IR; recorded using $\mathrm{KBr}$ wafer on a Bomem MB series. The initial basal spacing in the fiber matrix is an important parameter for the determination of the potential for polymer intercalation. This was determined by X-ray diffractometer for ' 'p', 'c' and p-c blended fabrics treated with nano-copper sol. The scans were performed for each sample and the values are reported for the basal spacing. The X-ray diffraction patterns were obtained using diffractometer $\mathrm{D} 8$ advance with $\mathrm{CuK} \alpha$ radiation $(\lambda=1.54 \AA)$.

\section{Dyeing of untreated and treated woven fabrics with natural dye}

A study on the dyeing behavior using Myrobolan on woven fabrics loaded with copper nano sol was also done, in order to ascertain the change in their dyeing performance. This was executed on laboratory scale instrument, applying exhaust dyeing technique and maintaining constant dye bath temperature (Paramount instruments Pvt. Ltd., India). The dye bath liquor containing natural dye $20 \%$ (on weight of fabric-owf) and acetic acid $\sim 2 \%$ (owf) was added to maintain dye bath $\mathrm{pH}$ of 5.5 in case of 'p' fabric whereas $2 \%$ (owf) sodium carbonate was added while dyeing 'c' fabric; maintaining material-to-liquor ratio of 1:40. Dyeing was started at room temperature and gradually 
raised to boil within $15 \mathrm{~min}$; continued till $30 \mathrm{~min}$ at same temperature. Finally the samples were thoroughly washed and air-dried.

Dyeing of $\mathrm{p}-\mathrm{c}$ blend fabric was initially started with $20 \%$ (owf) natural dye; the temperature was gradually raised to boil within $15 \mathrm{~min}$ and continued for $30 \mathrm{~min}$. 2\% (owf) sodium carbonate was then added to the dye bath and the dyeing was continued further for 15 more minutes. The samples were thoroughly washed, neutralized, and dried.

The dyed samples were assessed for $K / S$ values using computer colour matching system (Spectra scan 5100 RT Spectrophotometer, Premier Color scan Instrument Pvt. Ltd., Mumbai/India). The light fastness of the dyed samples was tested on Fad-o-meter (FDA-R, Atlas Material Testing Technology LLC, Chicago, Ill/USA) and the wash fastness test of the samples was performed as per ISO-2 test methods in launder-o-meter (Digi.wash, Paramount Scientific Instruments Pvt Ltd., New Delhi/India). The samples were evaluated for the rating in terms of colour change.

\section{Results and discussion}

\section{Morphological analysis of nanoparticles}

Figure 1 shows the scanning electron micrographs of nanoparticles sample. The average size of nanoparticles as seen from the scale of the photograph, is approximately in the range of $90-150 \mathrm{~nm}$ which is further confirmed by particle size analysis on Zeta particle size analyzer as shown in Fig. 2. It can also be seen from the same figure that the shape of synthesized particles is spherical.

\section{Elemental analysis of nanoparticles}

Elemental analysis of nanoparticles was performed using the scanning electron microscope with oxford-Inca software. The spectrum recorded for the particle is shown in Fig. 3, which confirms the presence of copper along with oxygen; giving indication that the nano particles are in their oxide form $\left(\mathrm{CuO}_{2}\right)$. The peaks for $\mathrm{Au}$, carbon $(\mathrm{C})$ and Sodium $(\mathrm{Na})$ are visible.

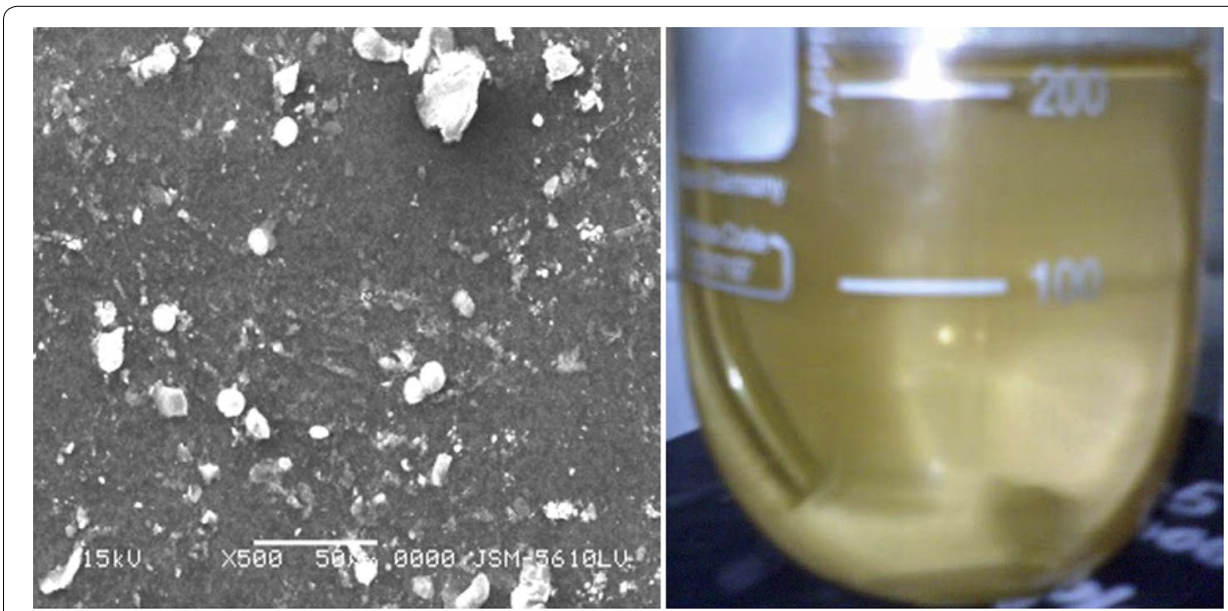

Fig. 1 Scanning electron microphotographs of copper nano particles 


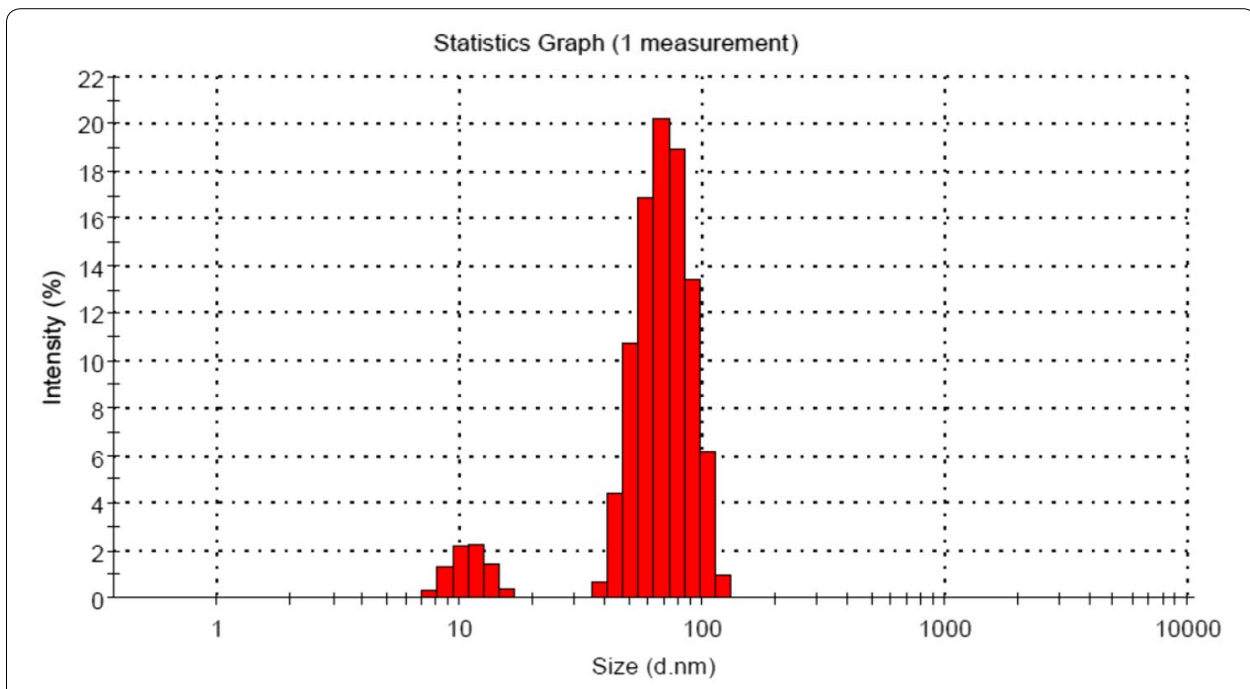

Fig. 2 Particle size distribution of synthesized copper nano particles on Zeta particle sizer
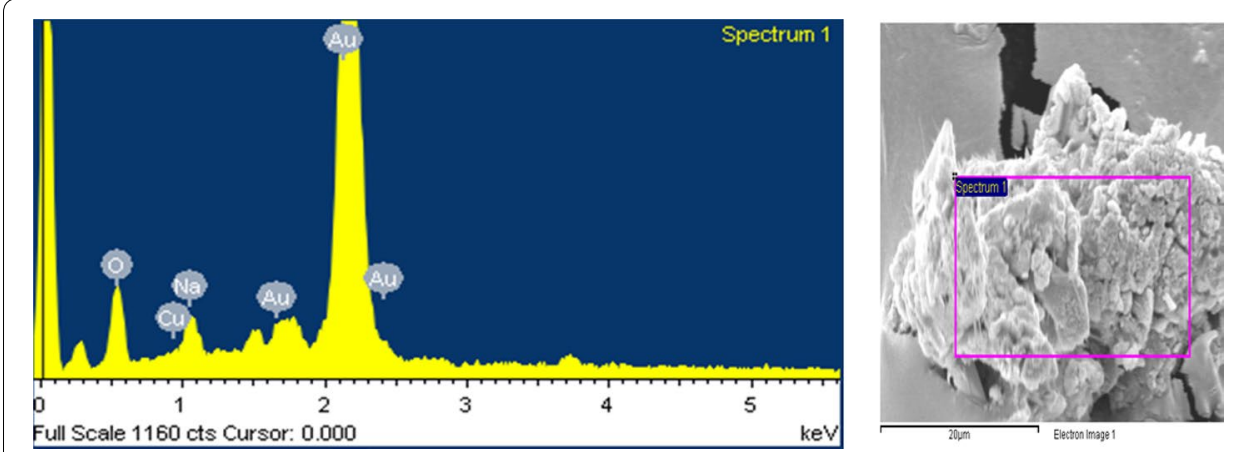

Fig. 3 EDS spectra of copper nano particles

\section{Surface morphology of nano copper loaded fabric}

The surface morphology of copper loaded 'p', 'c' and p-c fabrics is shown in Fig. 4 a, b and $\mathrm{c}$ respectively. The nano scale copper particles can be seen distributed on the entire fabric surface for all the fabric samples. However in case of polyester minor agglomeration is seen from the microphotographs. The particle size plays a primary role in

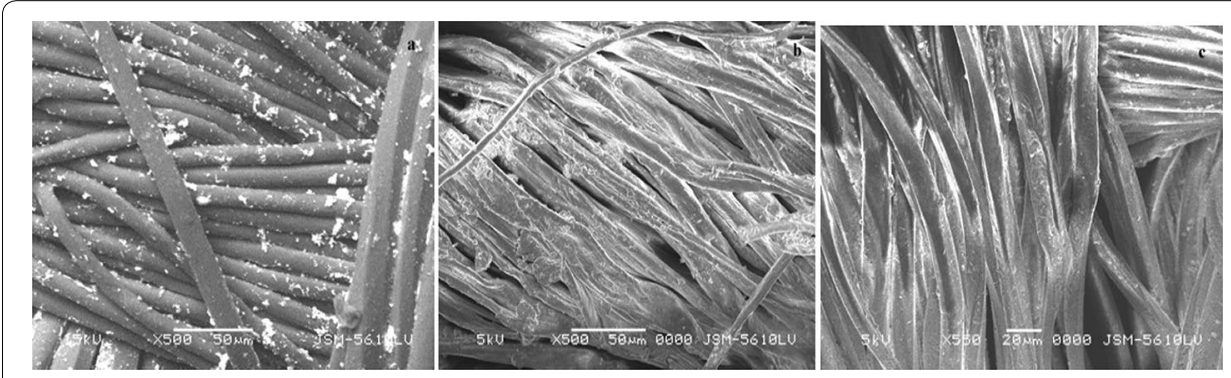

Fig. 4 SEM microphotographs of $\mathbf{a}$ polyester $\mathbf{b}$ cotton and $\mathbf{c}$ polyester-cotton blend fabric with copper nano particles 
determining their adhesion to the fabric. However the nano particles in agglomerate form remain smaller than the polymer matrix. It is reasonable to expect and assume that the particles whether in agglomerated form or individual can penetrate deeper and adhere strongly on/into the fabric matrix.

\section{Fourier Transform Infrared analysis}

Figures 5a, b, c and 6a, b, c shows FT-IR spectra of untreated and treated 'p', 'c' and p-c blend fabrics respectively. The 'p' fabric (Fig. 5a) shows typical band characteristics due to the presence of different functional groups like: $\mathrm{CH}_{2}$-anti-symmetric stretching at wavelength of $2945 \mathrm{~cm}^{-1}$, carbonyl bond stretching at wavelength of $1725 \mathrm{~cm}^{-1}$, standard absorption can be seen at wavelength of $1410 \mathrm{~cm}^{-1}$ due to $\mathrm{OH}$ bond (Ibrahim et al. 2010). Besides these, $\mathrm{CH}$-stretching second overtone at wavelength of $1143 \mathrm{~cm}^{-1}$, $\mathrm{O}-\mathrm{CH}_{2}$ stretching at wavelength of $973 \mathrm{~cm}^{-1}$, and benzenoid group at wavelength of $868 \mathrm{~cm}^{-1}$ are also visible. After treatment no significant change can be observed in the absorption spectrum (Fig. 6a). However minor changes in the peak values recorded can be attributed to the given copper nano treatment.

Figure $5 \mathrm{~b}$ shows the FT-IR spectra of the untreated 'c' fabric samples. The fabric samples show a strong absorption band between the wavelengths of $3000-3500 \mathrm{~cm}^{-1}$. The vibrations located at $1161 \mathrm{~cm}^{-1}$ can be attributed to the anti symmetric bridge $\mathrm{C}-\mathrm{O}-\mathrm{C}$ stretching vibration, $1105 \mathrm{~cm}^{-1}$ can be attributed to the anti symmetric in-plane ring stretching band and $1056 \mathrm{~cm}^{-1}$ to $\mathrm{C}-\mathrm{O}$ stretching mode.

After treatment the absorption band at wavelength of $2918 \mathrm{~cm}^{-1}$ becomes more prominent (Fig. 6b) in case of ' $c$ ' fabrics. Most of the peaks match each other almost exactly except the peak created at $2918.82 \mathrm{~cm}^{-1}$. It thus confirms the presence of hydrogen bond due to cellulosic nature of the parent fabric. This absorption band can be attributed to the asymmetric vibrations of $-\mathrm{CH}_{2}$ bonds. The broad absorption peak at around $3430 \mathrm{~cm}^{-1}$ is caused by the absorbed water molecules since the nano crystalline material exhibits a high surface to volume ratio and thus absorbs more amount of moisture. It is known that the usual absorption pattern in this region can be attributed to the intermolecular and intra-molecular hydrogen bonds (Ibrahim et al. 2010) of which absorption peak at $3335 \mathrm{~cm}^{-1}$ is due to intermolecular hydrogen bond.

Figure $5 \mathrm{c}$ shows the FT-IR spectra of untreated $\mathrm{p}-\mathrm{c}$ blended fabrics. The $\mathrm{OH}$ and $\mathrm{C}=\mathrm{O}$ absorption band at 3500 and $1600 \mathrm{~cm}^{-1}$ is respectively due to $\mathrm{OH}$ bond stretching and anti-symmetric stretching of carbonyl group present; attributed to the presence of cotton component. The anti-symmetric stretching band at $2945 \mathrm{~cm}^{-1}$ is due to $\mathrm{CH}_{2}$ bond, carbonyl bond stretching at $1725 \mathrm{~cm}^{-1}$, the standard stretching bond of $\mathrm{OH}$ at $1410 \mathrm{~cm}^{-1}$, O$\mathrm{CH}_{2}$ stretching at $973 \mathrm{~cm}^{-1}$ and benzenoid group (Das et al. 2009) at $868 \mathrm{~cm}^{-1}$ are present by default. It will be seen that the absorption spectrum of treated $\mathrm{p}-\mathrm{c}$ blended fabric samples does not show much of change (Fig. 6c). However on treatment with copper nanoparticles, additional absorption bands can be noticed at 2922.50, 1408.84, 1339.09, 894.39 and $871.81 \mathrm{~cm}^{-1}$ while other absorption spectrum remains unchanged. From results obtained for ' $p$ ' and 'c' fabrics, it becomes clear that the copper nano treatment was able to influence the cotton component while the polyester component was least affected. The changes thus observed in the absorption spectrum after treatment for p-c blended fabrics (Fig. 6c) may be due to the changes that the cotton component may have undergone. 
Kanade and Patel Fash Text (2017) 4:10

Page 7 of 12

a Untreated Polyester

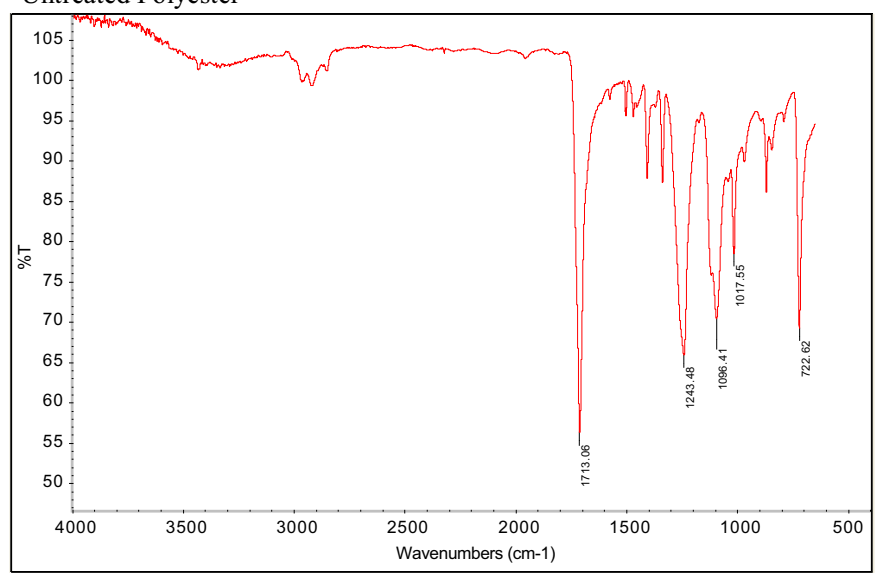

b Untreated Cotton

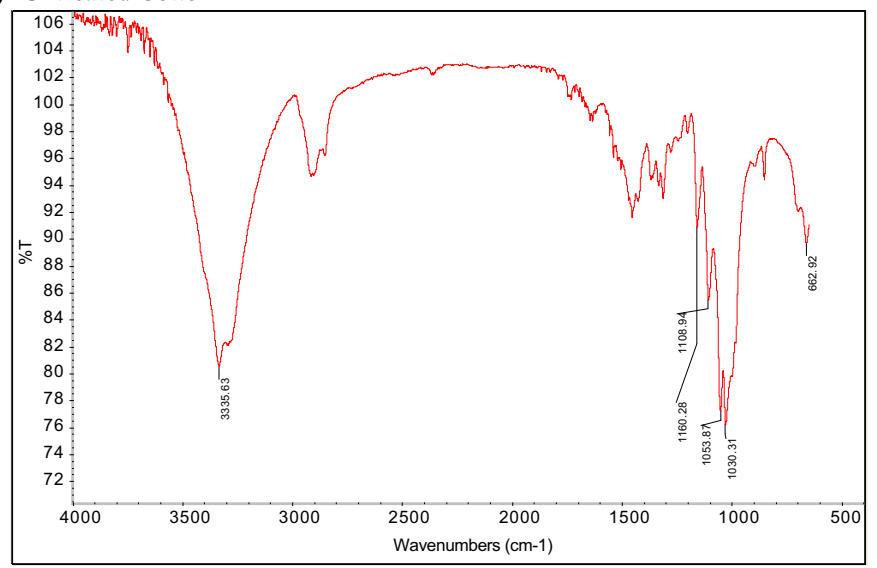

C Untreated PC blend

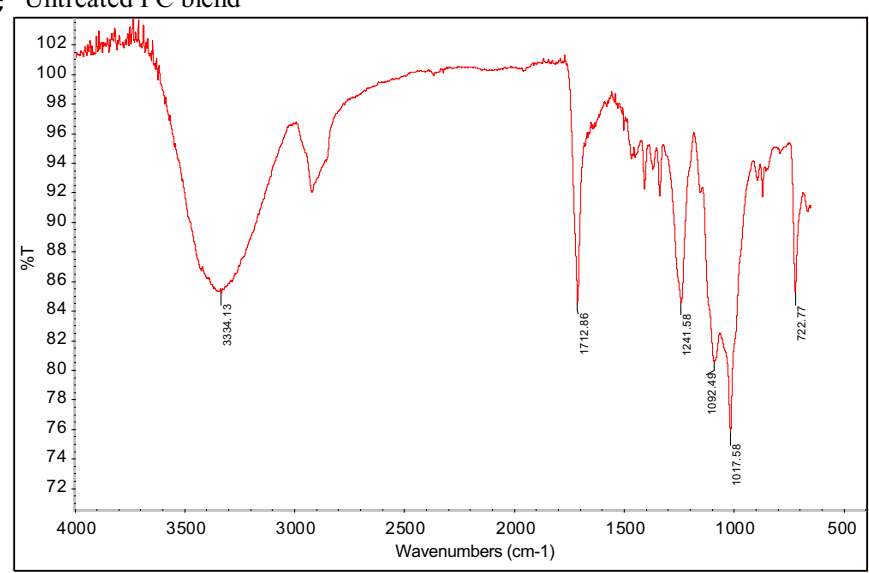

Fig. 5 a FT-IR spectrum of untreated polyester fabric sample. $\mathbf{b}$ FT-IR spectrum of untreated cotton fabric sample. c FT-IR spectrum of untreated polyester-cotton fabric sample 
a $\mathrm{Cu}$ nano treated polyester

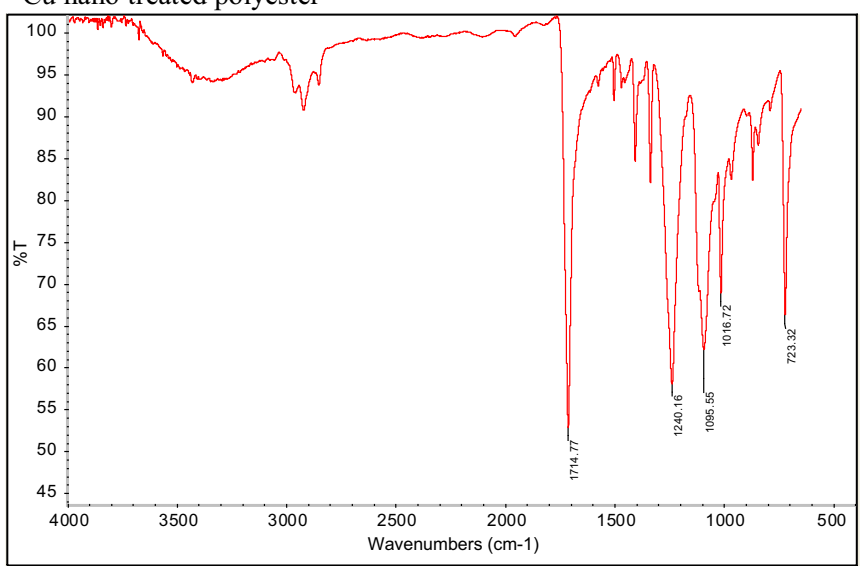

b $\mathrm{Cu}$ nano treated Cotton

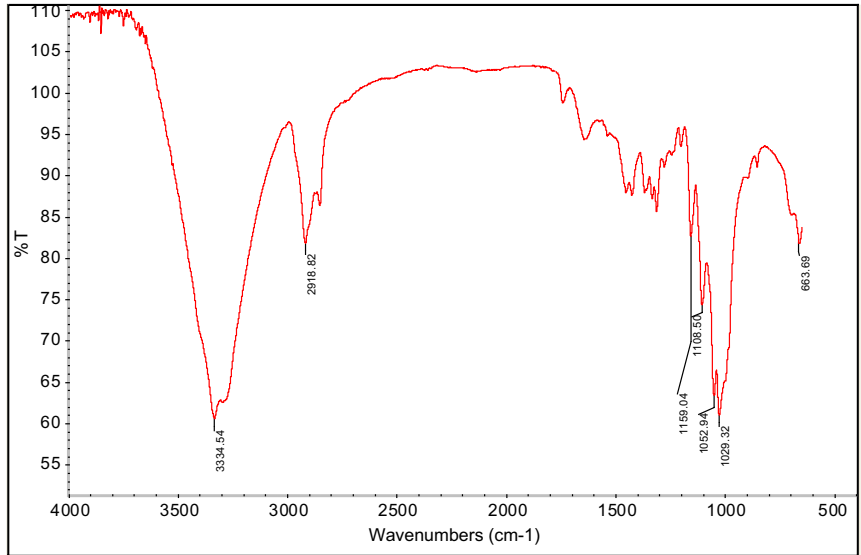

C $\mathrm{Cu}$ nano treated $\mathrm{PC}$ blend

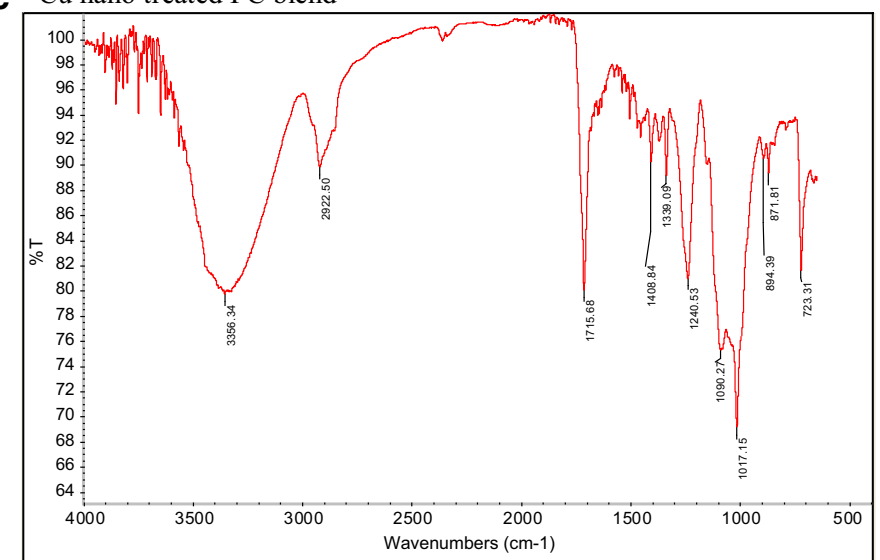

Fig. 6 a FT-IR spectrum of treated polyester fabric sample. b FT-IR spectrum of treated cotton fabric sample. c FT-IR spectrum of treated polyester-cotton fabric sample

\section{Elemental analysis of copper nano coated fabrics}

Elemental analysis of treated woven fabrics on SEM is in form of spectra as shown in Fig. 7a, b and c. Presence of copper was confirmed by the elemental analysis curve for individual fabric samples. The inserted data in corresponding figures is the overall percentage of copper added as a result of the treatment given to the fabrics. 


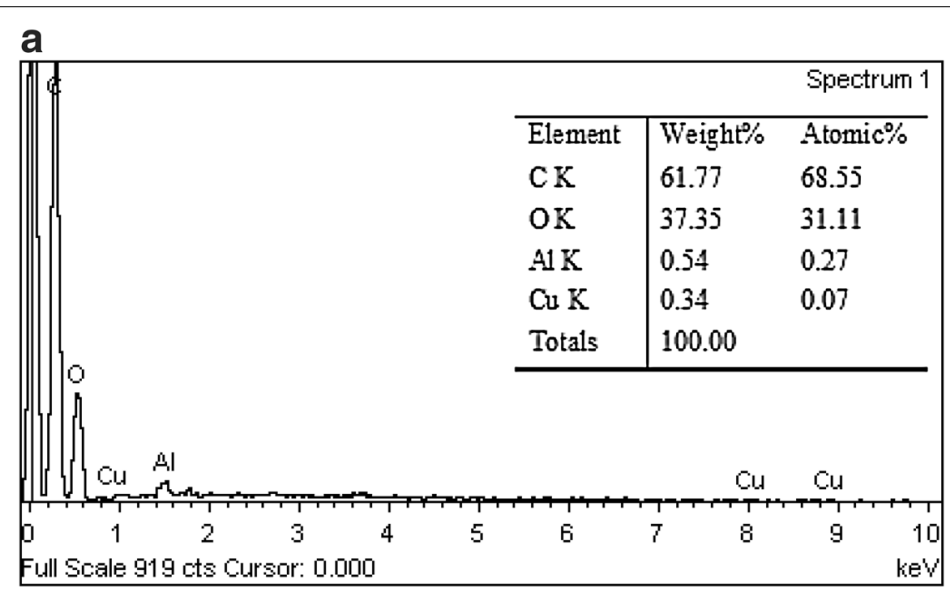

b

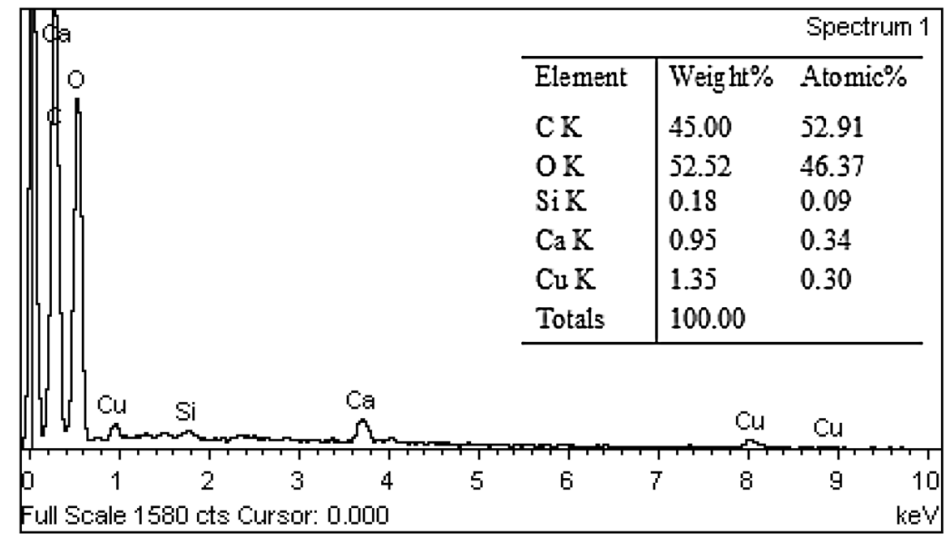

C

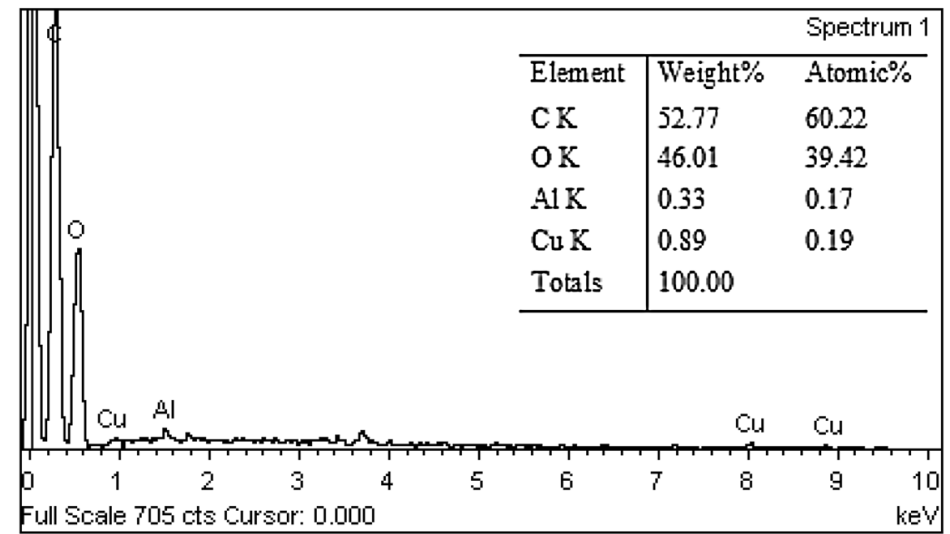

Fig. 7 a Elemental analysis of copper nano sol coated polyester fabric. b Elemental analysis of copper nano sol coated cotton fabric. c Elemental analysis of copper nano sol coated polyester cotton blended fabric

\section{XRD analysis of copper nano loaded fabrics}

The nature of copper nano coated woven fabrics was studied with the aid of X-ray diffraction as shown in Fig. 8a, b and c. Three peaks at $2 \theta$ values of 42.91, 51.02, and 73.96 degrees corresponding to (111), (200) and (220) planes of copper is observed. The XRD study confirms/indicates that the resultant particles are copper nanoparticles (Chattopadhyay and Patel 2013) and also indicates that they are crystalline in nature. 

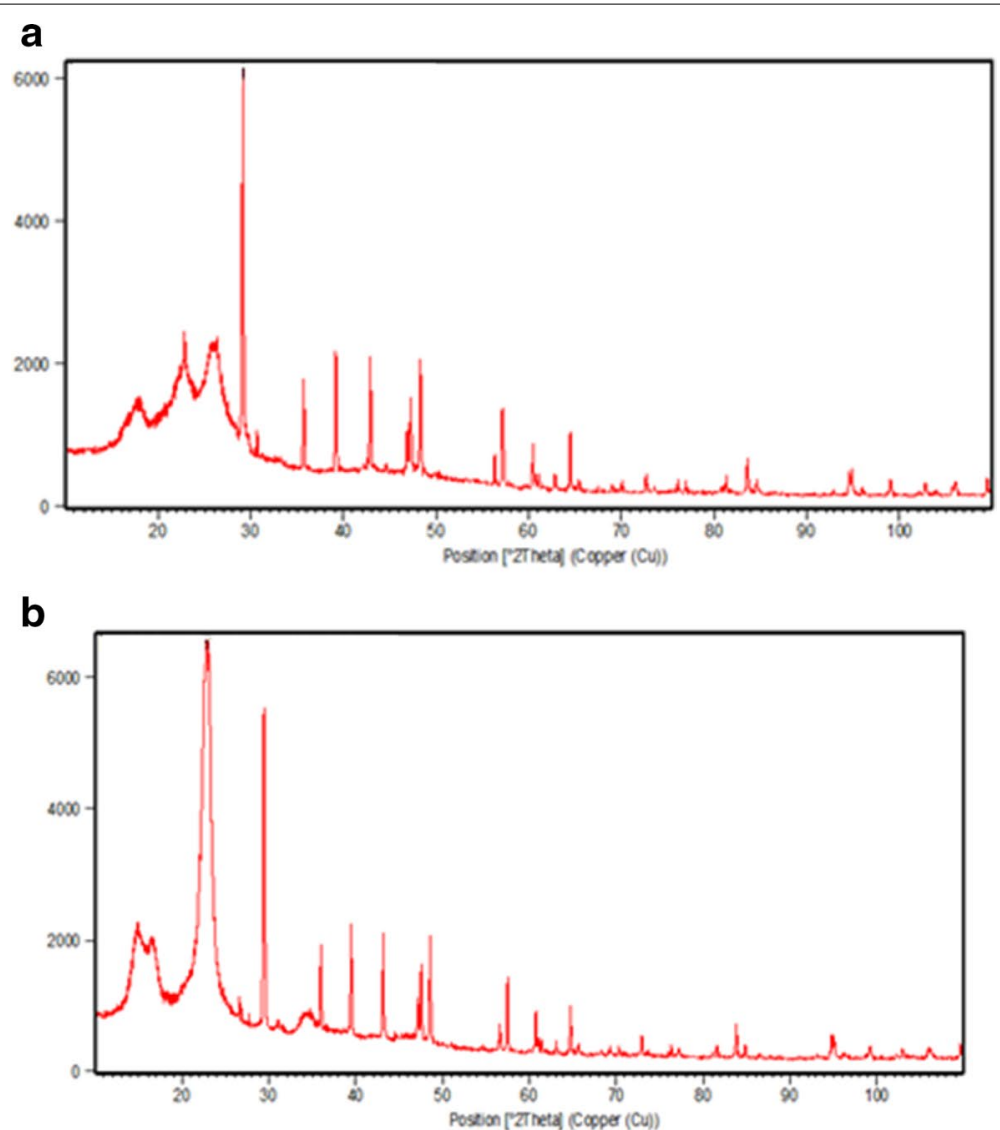

C

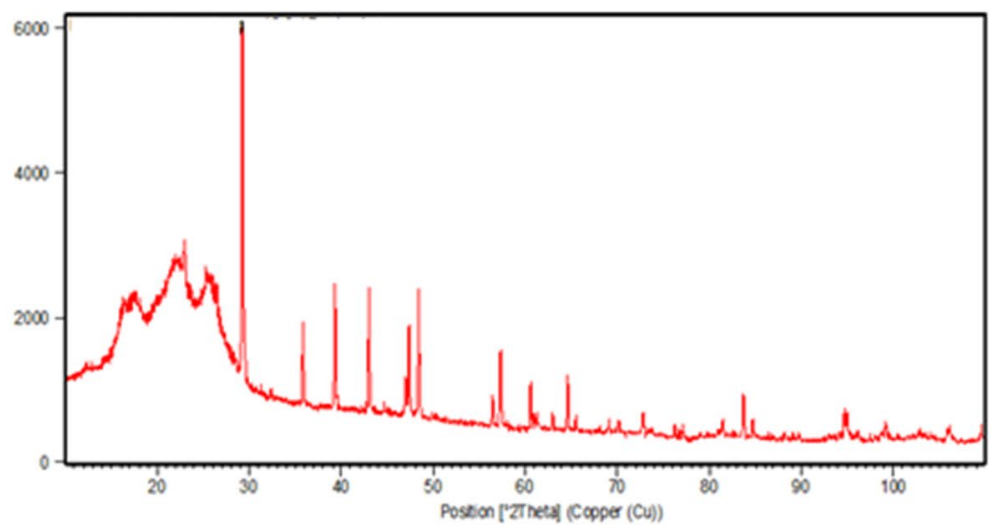

Fig. 8 a XRD pattern for copper nano treated polyester fabric. b XRD pattern for copper nano treated cotton fabric. c XRD pattern for copper nano treated $p-c$ fabric

Table 2 shows results obtained from the XRD spectrum for the treated woven fabrics. The $2 \theta$ values for all of treated fabrics are similar; ' $\mathrm{p}$ ' and $\mathrm{p}-\mathrm{c}$ blended fabrics show the maximum relative intensity.

It has also been observed that the flex width and $\mathrm{d}$-spacing value in polyester-nano copper structure was higher compared to the cotton-nano copper structure or $\mathrm{p}-\mathrm{c}$ blended-nano copper structure. The d-spacing value of cotton-nano copper structure is lower than polyester- nano copper structure. It may be due to the trapping of copper 
Table 2 XRD analysis of Cu loaded polyester, cotton and P-C blend fabric

\begin{tabular}{llllll}
\hline Sample & $\mathbf{2 \theta}$ & D-spacing & Flex width & Height & Rel. intensity \\
\hline Polyester & 29.12 & 3.06 & 1065.43 & 4782.67 & 100.00 \\
Cotton & 29.43 & 3.03 & 1032.92 & 4636.75 & 83.38 \\
P-C blend & 29.29 & 3.05 & 1200.38 & 4849.64 & 100.00 \\
\hline
\end{tabular}

Table 3 Colour strength values of woven fabrics dyed with natural colourant

\begin{tabular}{|c|c|c|c|}
\hline \multirow[t]{2}{*}{ Fabric sample } & \multirow[t]{2}{*}{ Colour strength $(K / S)$ values } & \multicolumn{2}{|c|}{ Fastness ratings } \\
\hline & & LF & WF \\
\hline Untreated polyester & 1.24 & 7 & $4-5$ \\
\hline Polyester treated with copper nano & 1.96 & $6-7$ & 4 \\
\hline Polyester treated with $\mathrm{CuSO}_{4}$ & 2.33 & $6-7$ & $4-5$ \\
\hline Untreated cotton & 3.45 & $6-7$ & 4 \\
\hline Cotton treated with copper nano & 5.35 & $6-7$ & $4-5$ \\
\hline Cotton treated with $\mathrm{CuSO}_{4}$ & 5.87 & $6-7$ & 4 \\
\hline Untreated P-C blend & 2.47 & 6 & 4 \\
\hline $\mathrm{P}-\mathrm{C}$ blend treated with copper nano & 2.51 & $6-7$ & 4 \\
\hline $\mathrm{P}-\mathrm{C}$ blend treated with $\mathrm{CuSO}_{4}$ & 4.26 & $6-7$ & 4 \\
\hline
\end{tabular}

K/S Colour Strength value, LF Light Fastness, WF Washing Fastness

nanoparticles inside the 'p' polymer matrix which results in increased intermolecular spacing while in ' $\mathrm{c}$ ' and $\mathrm{p}-\mathrm{c}$ blended fabrics, the d-spacing value was found to be comparatively lower. The amorphous nature of cotton makes it incapable of trapping the nano sized copper particles.

\section{Effect of copper nano treatment on dyeing}

The copper nano-loaded woven fabrics treated with natural dye (Myrobolan 20\% owf depth of shade) were compared with the untreated samples. The results in Table 3 show that the $K / S$ values of the nano copper pretreated samples are higher than those of the corresponding untreated samples of woven fabrics. The higher $K / S$ values (Table 3) of nano-treated samples indicate that the presence of nano metal particles increases the dye affinity towards the material. The copper nanoparticles in the fabric thus act as mordant. The negatively charged dye anions get attracted towards the fiber probably due to the polarity developed in the metal particles by induction which results in better bonding between the dye and the fiber. The better coupling of the dye and the fiber is also reflected in the improvement in the colour fastness properties (Table 3). Thus copper nano pre-treatment not only improves the colour strength but also improves the colour fastness which is a major drawback of most of natural dyes.

\section{Conclusion}

Plain woven 'p', 'c' and p-c blended fabrics were coated with nano sized copper by paddry-cure method. The surface morphology of woven fabrics was characterized by SEM technique and shows uniform distribution of nanoparticles throughout the fabric surface. The coated woven fabrics were further characterized by EDS and FT-IR technique; 
confirming the presence of copper nanoparticles on/in coated woven fabric samples. The structure of the prepared composite woven fabrics was analyzed by X-ray diffraction technique, which indicates that the $\mathrm{d}$-spacing value of polyester polymeric structure was higher than the highly amorphous structure of cotton and $\mathrm{p}-\mathrm{c}$ blended fabrics. In case of dyeing the improvement could not exceed that obtained using bulk conventional mordanting agent but introduction of nano copper in the system enhanced the wash fastness of dyed fabric samples. Dyeing of the nano copper loaded woven fabrics with natural dye (Myrobolan) also proved to be beneficial.

\section{Authors' contributions}

PK acquired the fabric samples and carried out the structural and elemental testing of fabric samples. BP gave copper nano treatment to the fabric samples and analysed the test results. The manuscript was jointly drafted by both the authors. Both authors read and approved the final manuscript.

\section{Competing interests}

The authors declare that they have no competing interests

Received: 11 August 2016 Accepted: 5 January 2017

Published online: 28 May 2017

\section{References}

Bhattacharya, S. S., \& Chaudhari, S. B. (2014). Study on structural, mechanical and functional properties of polyester silica nanocomposite fabric. International Journal of Pure and Applied Science and Technology, 21, 43-52.

Chattopadhyay, D. P., \& Patel, B. H. (2009). Improvement in physical and dyeing properties of natural fibers through pretreatment with silver nanoparticles. Indian Journal of Fiber \& Textile Research, 34, 368-373.

Chattopadhyay, D. P., \& Patel, B. H. (2010). Effect of nano-sized colloidal copper on cotton fabric. Journal of Engineered Fibers and Fabrics, 5, 1-6.

Chattopadhyay, D. P., \& Patel, B. H. (2011). Modification of cotton textiles with nanostructural zinc particles. Journal of natural fibers, 8, 39-47.

Chattopadhyay, D. P., \& Patel, B. H. (2012). Influence of copper nanocolloids on jute fiber. Textile Asia, 43, 19-21.

Chattopadhyay, D. P., \& Patel, B. H. (2013). Effect of Cu-nano colloid treatment on the properties of Wool and Silk. Textile Review, 8, 67-70.

Chattopadhyay, D. P., \& Patel, B. H. (2014a). Functional properties of silver nano-sol treated wool and silk fabric. Man-made Textiles in India, 42, 340-344.

Chattopadhyay, D. P., \& Patel, B. H. (2014). Nano metal particles: Synthesis, characterization and application to textiles. Manufacturing nanostructures, $1^{\text {st }}$ edn. Manchester: One Central Press (OCP).

Das, R., Nath, S. S., Chakdar, D., Gope, G., \& Bhattacharjee, R. (2009). Preparation of silver nanoparticles and their characterization. Journal of Nanotechnology, 5, 1-6.

http://www.intechopen.com/books/fourier-transforms-new-analyticalapproaches-and-ftir-strategies/applications-offourier-transform-infrared-spectroscopy-to-study-cotton-fibers. Accessed 1 Oct 2015.

Ibrahim, S. F., El-Zaher, N. A., \& Micheal, M. N. (2010). Characterization and evaluation of physico-chemical properties of polymeric fabrics treated with UV/ozone. Research Journal of Textile and Apparel, 14, 59-71.

Patel, B. H., \& Chattopadhyay, D. P. (2007). Nano-particles \& their uses in textiles. The Indian Textile Journal, 118, 23-31.

Patel, B. H., Chaudhari, S. B., \& Patel, P. N. (2014). Nano silica loaded cotton fabric: Characterization and Mechanical testing. Research Journal of Engineering and Science, 3, 19-24.

Patel, B. H., \& Patel, P. N. (2012). Synthesis and application of nano-sized $\mathrm{SiO}_{2}$ to textiles: a review. International Dyer, 5 , 35-39.

Shaikh, T. N., Chaudhari, S. B., Patel, B. H., \& Patel, M. (2015). Study of conductivity behaviour of nano copper loaded nonwoven polypropylene based textile electrode for ECG. International Journal of Emerging Science and Engineering, $3,11-14$. 